\title{
Editorial
}

\section{Reproductive Health and Rights and the Quest for Social Justice}

WENDY HARCOURT

This issue focuses on reproductive rights and health as a contribution to the Cairo +5 process that is reviewing the impact, achievements and goals set by the International Conference on Population and Development (ICPD) held in Cairo, September 1994. As the first issue of volume 42, the discussion on reproductive rights and health brings to the fore human centred and gender aware challenges to development policies grappling with the impact of globalization and economic crises.

Continuing along the journal's quest for social justice, the four issues of volume 42 aim to reassert the importance of reproductive rights, health, environment and politics alongside the development issues of trade, finance and economic policy. They are placed firmly at centre stage, analytically and practically in global politics. Accordingly, we will be inviting readers to enjoy in future issues of volume 42 discussions on: environmental politics, continuing the debate around sustainable livelihoods (Development 42.2); the politics of aid in the age of globalization, looking at the political rationale for development cooperation given the realities of today's world (Development 42.3); and, with the collaboration of the World Health Organization and the Rockefeller Foundation, a special issue on globalization and public health (Development 42.4).

The focus of Development 42.1 on reproductive rights and health is strategically timed as a contribution to the Cairo +5 process. It aims to show readers how the issue of population and development viewed from a cultural and gender perspective is not a peripheral women's issue, but a vitally important contribution to new thinking about development policy as a whole. The process leading up to Cairo, and the years following the meeting, indicate how actors in the reproductive rights and health field have gathered a tremendous amount of new knowledge, undertaken worldwide advocacy through effective networking and shown great ability to accommodate sensitively diverse cultural positions. 
All of which has led to the success of the international women's movement to strategize and campaign across regions in order to challenge local, national and international level policies. It also signals the political strength of the international women's movement in challenging and changing world development agendas. The core argument of the journal is that such initiatives are not just changing profoundly approaches to population but are leading the rethinking of development policy and political institution building.

The major achievement of Cairo is undoubtedly placing reproductive rights and health and women's empowerment centre stage within a democratic and human rights framework. The Cairo +5 process is now assessing just how those commitments have been put into place.

From the articles several interesting if contentious issues are emerging in the post-Cairo assessment. First is the risk of hinging the whole Cairo agenda on reproductive rights and health. When looking at how to put into action such an agenda, reproductive rights and health becomes a more slippery concept as it is interpreted by diverse cultures and geo-political positions embedded in different economic situations. In order to produce international level policy agreements these differences had been subsumed in the complex negotiation process that produced the Programme of Action. It appears, at least on paper, that Cairo brought about a transformation of cultural norms in relation to reproductive rights. But whose cultural norms set the basis for the agreement? During Cairo the assumption of those opposing reproductive rights and health, and in particular sexual reproductive health and the autonomy of women, was that this was a northern feminist agenda imposed through international mechanisms on other cultures. Dissenting voices at Cairo and since (including the articles written here by women from southern regions) reveal that this is not the case. There are different but equally strong womencentred agendas in the South and East that build from their own history and cultural norms fully cognizant with the economic and political situation in which they are placed. Such agendas are decided within sophisticated and realistic analytical frame- and private and the micro and macro environment, fully aware of the diversity of cultural patterns while still seeing reproductive rights as a critical issue. And it is the insights into women's lives in the South and the East provided by these frameworks that have led and given authority to the post-Cairo discussions, and have been in the front line as the Cairo consensus is pushed into action.

During the ICPD and now with the Cairo +5 review process, the differences between North, South and East are recognized and thrashed out, with all sides listening to the others. Actors in the international women's movement, while acknowledging their different positions, have learnt very effectively to pull together strategically. They show the way for others in the goal to forge more democratic ways of working and new political institutions on the pathway to social justice.

A further contentious issue that continues to be evident in the post-Cairo scenario is how to put into practice a participatory and empowering set of reproductive health practices. Cairo's message is clear-women have to be the subject, not the object, of reproductive health services. This makes the role of the expert outsider, woman or man, intervening into other women's lives much more delicate. Women researchers, sensitive policy-makers, community services workers and NGO activists have now to think creatively about how to provide reproductive health knowledge or services in order for women (and men) of all ages and cultures to make self-determined choices. This implies the difficult task of changing bureaucracies, medical establishments and well meaning but insensitive agencies with a population policy agenda (and target) to push in order to foster self-esteem and provide real choices for those using the service.

Such considerations apply to another contentious issue: the ambiguity around the use of modern reproductive technology as opposed to traditional customs. From Cairo and the evidence given in the articles, the efficacy of reproductive technology needs to be separated out from the oppressive delivery of medical and bureaucratic organizations. It is important to bring out the politics behind how a technology is conceived and practised. It is equally important to recognize the appropriateness of technology for different groups 
of women and men in their specific life stages and cultural context. In some cases this could mean rejecting today's reproductive technologies in favour of less interventionist tools. But recognizing the drawbacks of some medical technologies and their delivery does not mean celebrating the nonwestern technological world of childbirth. This, in any case, hardly exists. In the post-Cairo scenario the point is that in pursuing a reproductive health and rights framework we have to take on board the need to transform health and medical institutions in order to incorporate social and cultural requirements as defined by women at the local, national and international levels. This political strategy will hopefully lead to a varied number of reproductive life patterns reflecting not only western medical technology but past traditional practices which women feel are adaptable and still useful.

In shifting population policies towards a peoplecentred reproductive health framework, the postCairo aim is to create conditions where women are not imposed upon but can select what they wish from outside influences. External intervention should be enriching not overwhelming. For the expert that suggests more careful preparation and knowledge of the local environment in order to ensure that new information and technologies are fully compliant with local women's and men's own experience and culture. Such an approach would include the right for women and men to resist, in a discerning and informed way, policies that they perceive as harmful to themselves and their community. The ability for those participating in reproductive health programmes to set priorities and make choices also demands a sense of direction and purpose which is not solely an individual but a community one. Essentially this suggests that reproductive health has to be part of a political agenda which is conversant with the economic and social realities being faced and in challenging conventional population and development policy is contributing to the move towards just and equitable social relations.

This leads us to one of the major criticisms to emerge post-Cairo - that the battle won over the reproductive rights agenda based on a human rights and democratic framework fatally pushed to one side the more politically contentious and difficult issues of economic development. In the Cairo +5 process the 'enabling environment' is now being much more thoroughly looked at, putting the framework of reproductive rights and women's empowerment within the context of the global economic crisis and questions around development itself. Unlike in Cairo where economic growth at all costs was never questioned, postCairo the costs are all too evident. Governments that are forced by global imperatives to follow stringent market oriented policies are unable to provide women with the reproductive rights and services that Cairo promised. Market stringencies, continued structural adjustments, cuts in the welfare state and the globalizing market all disrupt severely the provision of reproductive health, education and medical services.

The external macro-economic environment is one major issue that is under discussion in the postCairo debate. Another challenge, taking us to another political level, is the question of how far issues can be raised in today's reactionary world of growing fundamentalism and uncertainty. How safe is it for women to raise publicly issues around reproductive health and rights? What must remain private? The premise that the 'personal is political' belongs to certain cultures and historical moments and cannot be applied to all women. As many of the articles in this issue show, putting Cairo into action reveals that women's positions and political agendas operate at different levels. While some women in some cultures can accommodate and actively promote an open discussion on sexuality and reproductive behaviour, others, for strategic reasons of survival, need to maintain a veil of silence. One of the most challenging issues within the international women's movement concerned with reproductive health and rights is how to accommodate the different parameters of private and public among cultures. Even if Cairo acknowledges that there is no one approach to creating women's access to safe and enjoyable reproductive rights and health practices, it is still a struggle to respect cultural diversity, particularly in the face of the such strong opposition of the Vatican and other religious states. Post-Cairo policy is, therefore, looking at how to create multiple safe spaces so that diverse women's views and choices can be aired 
and ultimately be fed appropriately into their communities and the national decision-making political sphere.

In mapping out the state of the debate on reproductive rights from the local and global continuums, we hope that this journal issue contributes to the debate surfacing and even disrupting the 'Cairo consensus'. Each section sets out to chart the ways different women's activist and research groups are working together as they move forward with the impetus of Cairo +5. The lead articles in 'Upfront' flag what has happened since Cairo in Brazil, Pakistan and Europe, reflecting how Cairo has consolidated or forged women-centred agendas. In the thematic section, contributions from around the world record preparations for the Cairo +5 process. 'SID On-line Dialogue' uses the material from SID's reproductive health projects with interviews of project partners in order to record their views of reproductive rights. The journal is also designed as a resource for those wishing to become engaged in the Cairo +5 discussions. 'Local/Global Encounters' and 'Window on the World' report on the myriad activities around the world involved in implementing the reproductive rights agenda. Following the 'Feature Book Review' that gives the assessment of seven books on Cairo, 'Book Shelf' presents useful journals, newsletters and websites that are covering reproductive rights and health.

This is our first 'on-line' issue and there are other interactive features. The hard work of members of SID-WID reproductive health projects and support from SID's donors have also allowed, for the first time, a collection of articles from the journal to be produced in six languages: Spanish, French, Italian, Portuguese, Urdu and Swahili. The debate sparked off by the articles here is also happening on-line through the SID-WID Forum on ICPD + 5 (www.sidint.org), and we cordially invite readers to join us there. 